\title{
Large genomic rearrangements of both $B R C A 2$ and $B R C A 1$ are a feature of the inherited breast/ovarian cancer phenotype in selected families
}

\author{
A M Woodward, T A Davis, A G S Silva, kConfab Investigators, J A Kirk, J A Leary
}

J Med Genet 2005;42:e31 (http://www.jmedgenet.com/cgi/content/full/42/5/e31). doi: 10.1136/jmg.2004.027961

\begin{abstract}
Introduction: A strong family history of breast and/or ovarian cancer can often be explained by small insertions, deletions, or substitutions in BRCA1 or BRCA2 and large genomic rearrangements in BRCA1. However, there is little evidence that genomic rearrangements are a major factor in $B R C A 2$ associated breast cancer and the frequencies of rearrangements in $B R C A 1$ in large clinic based populations are unknown.

Objective: To investigate the frequency of large genomic rearrangements in $B R C A 1$ and $B R C A 2$ in a large clinic based population at high risk of developing breast and/or ovarian cancer.

Methods: Multiplex ligation dependent probe amplification was used to comprehensively screen BRCA1 and/or BRCA2 in 312 index cases.

Results: Three novel deletions detected in BRCA2 were found exclusively in families with at least one case of male breast cancer. Novel rearrangements in BRCAl were detected mostly in families with both breast and ovarian cancer. Families with these mutations were significantly younger at average age of cancer diagnosis.

Conclusion: Screening for large genomic rearrangements in both BRCA1 and BRCA2 is strongly supported by this study, in particular in multiple case breast/ovarian families with a young age of onset (BRCA1) and families containing at least one case of male breast cancer (BRCA2).
\end{abstract}

lnheritance of a germline mutation in a cancer susceptibility gene accounts for $5-10 \%$ of all breast and ovarian cancer, and a higher proportion of cancers associated with a strong family history of the disease. From the initial linkage studies in the early 1990s it was predicted that mutations in BRCAI and $B R C A 2$ would account for a large proportion of multiple case families. ${ }^{1}$ However, despite extensive mutation analysis, the rate of detection of mutations in these genes rarely rises above $30 \%$ in the family cancer clinical setting and has never reached the expected high frequency, even in families with multiple cases of the disease in successive generations. Until recently, the testing of BRCA1 and BRCA2 has been focussed on the identification of point mutations or small deletions and insertions. ${ }^{2}$ Another mechanism of gene inactivation, namely the rearrangement of large tracts of genomic DNA, may be responsible for a proportion of the undetected mutations and many families previously found to be mutation negative might harbour hitherto undiscovered rearrangements. $^{3-5}$ Homologous recombination between repeated DNA sequences is believed to be a major cause of the genetic instability that results in genomic deletions, duplications, or other rearrangements. The high density of
Alu repeat sequences in BRCAI (42\%) and both Alu (20\%) and non-Alu $(27 \%)$ repetitive DNA in BRCA2 supports the likelihood that these genes may be susceptible to inactivation by homologous recombination. ${ }^{6}$

The first rearrangement described in BRCAl was a $1 \mathrm{~kb}$ deletion that included the loss of exon 17.7 Since that time, up to 30 different genomic rearrangements, both deletions and duplications, ranging in size from $510 \mathrm{bp}$ to $37 \mathrm{~kb}$, have been described throughout the BRCAl gene. ${ }^{3-5} 8-11$ The frequency of these rearrangements in families with strong family histories of breast and/or ovarian cancer ranges from $0.8 \%$ to $23 \%$, with an average frequency of $6-7 \%$. Despite the number of rearrangements detected to date, until recently the methods of detection were not capable of revealing all possible rearrangements. ${ }^{3812}$ Whilst the majority of the mutations are family specific, founder deletions have been identified in families of Dutch ancestry, and the duplication of BRCAl exon 13 has been observed in multiple families. ${ }^{5}{ }^{13}$

Less is known of the extent to which large genomic rearrangements in BRCA2 contribute to the development of cancer. To date, approximately 300 families have been investigated in a limited number of studies and six genomic rearrangements have been detected in BRCA2. ${ }^{14-20}$ Testing has primarily been by Southern analysis and only one recent study has used comprehensive screening methods capable detecting all large genomic rearrangements.

The prospect that some families, for whom mutation testing has so far yielded a negative result, may harbour large deletions and rearrangements provides a promising outlook for those engaged in clinical practice. If a causative mutation can be identified, then predictive testing can be performed to identify individuals who may benefit from increased surveillance, chemo-prevention, or prophylactic surgery aimed at minimising the risk of developing cancer. ${ }^{21}$ However, as the majority of studies performed to date have focussed primarily on small populations of specific ethnicity and very few have utilised comprehensive screening methodologies aimed at detecting all rearrangements, it is important to ascertain whether the frequency of rearrangements is high enough in a large clinic based population to warrant routine testing of multiple case families. Thus, the aims of this study were to document the frequency of novel large genomic rearrangements in BRCA1 and BRCA2 in a large, clinic based cohort of families in whom no BRCAl/2 mutations had previously been detected, and to ascertain whether testing for such rearrangements should be included in routine testing.

\section{METHODS}

The DNA of index cases from 312 families identified through family cancer services throughout Australia and New Zealand (either enrolled in the kConFab study (www.kconfab.org) or

Abbreviations: MLPA, multiplex ligation dependent probe amplification 
seen at Westmead Hospital, Sydney) was examined for the presence of novel large genomic rearrangements in BRCAl and/or BRCA2. These families generally have three or more family members affected by breast and/or ovarian cancer, or two or more with additional high risk features such as younger age at diagnosis (less than 40 years) or bilateral breast cancer. The majority of families analysed in this study had five or more individuals affected with either breast or ovarian cancer in the kindred (range, 2-14). All families were negative for mutations in BRCAl/2 after the screening of at least one family member.

All appropriate Institutional Research Ethics Committee approvals were obtained, in particular that of the host institution for the study, the Western Sydney Area Health Service Human Research Ethics Committee, Westmead, Australia. Ethical consent was obtained from all subjects included in the study.

Mutation analysis for novel large genomic rearrangements in $B R C A 1$ and BRCA2 was performed by the multiplex ligation dependent probe amplification (MLPA) technique that allows for relative quantification of multiple DNA fragments in a single reaction. ${ }^{22}$ The BRCAl and BRCA2 MLPA kits (MRCHolland, Amsterdam, the Netherlands) and the protocol for the final assessment of allele dosage were used as described by the manufacturer (www.mrc-holland.com). ${ }^{3}$ For all DNAs positive for a genomic rearrangement, testing was repeated on several occasions using independent DNA samples in independent assays. DNA sequence analysis of the appropriate ligation sites was performed for confirmation of any single exon deletions, to eliminate the possibility of an amplification artefact. Real time PCR amplification was employed to confirm differences between individuals with normal allele dosage and mutation positive individuals (data not shown).

Where RNA was available, RT-PCR and sequence analysis was performed to confirm any deletions, using the Titan one step PCR system (Roche Diagnostics Australia, NSW, Australia) (data not shown).

\section{RESULTS AND DISCUSSION}

BRCA1 MLPA analysis of genomic DNA from 271 affected individuals from families with a strong family history of breast and/or ovarian cancer resulted in the identification of six individuals with genomic rearrangements $(2.2 \%)$ (table 1 ) including three novel large genomic deletions involving exons 21-23, exon 3, and exon 5. Any family previously shown to be positive for the common duplication of BRCAl exon 13 was not included in the tested cohort and thus the true frequency of large genomic rearrangements in BRCAl in families where there is a strong family history of breast and/ or ovarian cancer may be greater than the $2.2 \%$ reported in this study.

Table 1 The frequency of large genomic rearrangements in $B R C A 1$ and $B R C A 2$ in a large clinic based population previously negative for BRCA $1 / 2$ mutations

\begin{tabular}{lll}
\hline & \multicolumn{2}{l}{$\begin{array}{l}\text { Frequency of genomic } \\
\text { rearrangements }\end{array}$} \\
\cline { 2 - 3 } Family type & BRCA1 & BRCA2 \\
\hline Female breast cancer only & $2 / 179(1.1 \%)$ & $0 / 65$ \\
Female breast and ovarian cancer & $4 / 83(4.8 \%)$ & $0 / 59$ \\
Female and male breast cancer & $0 / 9$ & $3 / 25(12 \%)$ \\
Total & $6 / 271(2.2 \%)$ & $3 / 149(2 \%)$ \\
\hline
\end{tabular}

The deletion of exons 21,22 , and 23 of BRCAl was detected in four independent families. This out-of-frame deletion is predicted to result in truncation of the BRCAI protein at codon 1770. Haplotype analysis was performed for three of those families and there was no evidence of a shared haplotype. Thus, the repeated observation of this mutation is most likely due to local genomic instability in a region where there is a very high proportion of Alu sequence rather than the presence of a common founder mutation in the Australian population. By contrast, the lack of evidence for any involvement in Australian families of the BRCAl mutations commonly observed in the Dutch population further supports the role of those particular mutations as unique founder mutations in families of Dutch ancestry. ${ }^{5}$

The deletion of BRCAl exon 5 was shown by PCR and sequence analysis of the cDNA to have resulted in the inframe deletion of the whole of exon 5 with a predicted loss of 26 amino acids from the translated protein. The out-of-frame deletion of exon 3 is predicted to result in a truncation at codon 27. Both deletions lie within the RING domain of $B R C A l$ and are likely to have a negative impact on the function of the protein. Investigations aimed at determining the genomic breakpoints for these mutations (and those described below) and the subsequent development of more simple PCR approaches for the detection of these deletions are on going within the respective clinical/laboratory units responsible for the families.

One of the strongest predictors of the likelihood of carrying a BRCAl mutation is considered to be the occurrence of both breast and ovarian cancer in an individual within families possessing multiple cases of breast and/or ovarian cancer, and young age at breast cancer diagnosis. ${ }^{11}{ }^{23}$ In this study, whilst it is true that a greater proportion of the mutations in $B R C A 1$ were observed in the families affected by both breast and ovarian cancer $(4.8 \%)$ (table 1$)$, compared with $1.1 \%$ in site specific breast cancer families, this difference did not reach significance $(p=0.08$, Fisher's exact test) and only one of the four mutation positive individuals from a breast/ ovarian family was from a family in whom an individual was affected by both breast and ovarian cancer. There were 16 families that likewise had an individual affected by both breast and ovarian cancer where no mutation was detected, thus this phenotype was not a strong predictor of detecting a large genomic rearrangement in BRCAl in previously mutation negative families. Furthermore, the presence of multiple primary breast cancers in an individual was also not predictive of a mutation in either BRCAl or BRCA2.

The affected women carrying genomic rearrangements in $B R C A l$ were typically from families with a young average age of onset of cancer diagnosis in the family ( 43 years) that was significantly different from those families in the study in whom no genomic rearrangement could be detected (51.4 years) $(\mathrm{p}=0.004, \mathrm{t}$ test; $\mathrm{p}=0.003$, Mann-Whitney test). This observation may be clinically useful in directing the testing for BRCAl large genomic rearrangements.

MLPA analysis of BRCA2 resulted in the identification of three individuals ( $2 \%$ ) with novel genomic rearrangements in the 149 families with a strong family history of breast and/or ovarian cancer that were tested. These rearrangements involved a deletion of exons 14, 15, and 16 in one family and the deletion of exons 1 and 2 in two families. Only one of these two families was suitable for haplotype analysis and therefore at this time no conclusions can be drawn regarding the independent nature of this novel rearrangement. Real time PCR amplification was used to confirm the deletion in the $5^{\prime}$ region of BRCA2 involving exons 1 and 2 (data not shown). The deletion of exons 14-16 is predicted to be an inframe deletion resulting in the loss of 266 codons in the translated protein. 
The contribution of large genomic rearrangements in $B R C A 2$ to the spectrum of all BRCA2 mutations observed in the families seen at Westmead Hospital or enrolled in the kConFab study (www.kconfab.org) is $2.3 \%$. This is in contrast to that observed for BRCA1, where $14.9 \%$ of all mutations observed in these families are large genomic rearrangements that include, but are not limited to, the duplication of exon 13 found in multiple families in addition to those rearrangements observed in this study. Thus, as predicted by the lower density of $A l u$ repeat sequences in $B R C A 2$, genomic rearrangements related to homologous recombination between $A l u$ repeat sequences does not appear to be as common a mechanism of gene inactivation for $B R C A 2$ as it is for BRCAI.

All individuals that were found to harbour a genomic rearrangement of BRCA2 were women affected by breast cancer and were members of families where a male relative was also affected by breast cancer. Three of 25 (12\%) such male/female breast cancer families were found to be positive for a deletion. This was significantly different from the rates observed for site specific female breast cancer families $(0 / 65)$ and families with breast and ovarian cancer histories (0/59) $(p=0.004$, Fisher's exact test). Although the strongest predictor for the occurrence of a BRCA2 mutation in a family with a strong family history of breast and/or ovarian cancer is the presence of a male affected by breast cancer, ${ }^{24}{ }^{25}$ it is nonetheless interesting to note the lack of these mutations in the other categories of families. There was no significant difference in average age of onset of cancer in families positive for a $B R C A 2$ mutation (47 years) compared with those with no detected BRCA2 mutation ( 51.5 years). The results of our study support those of a similar sized study recently reported by Tournier et $a l^{20}$ and if borne out by testing a larger series of patients, may indicate a case for the triage of families for BRCA2 testing in clinical practice.

The functional consequences of the mutations observed in this study are not known and cannot be determined in the absence of functional assays for either BRCA1 or BRCA2. However, the rearrangements either include known functional regions of the genes (exons 3 and 5 of BRCAl and the promoter region of $B R C A 2$ ) or cover extensive regions of the genes (exons 21-23 of BRCA1, exons 14-16 of BRCA2) and thus it is likely that they are causative of cancer susceptibility in the families in whom they were identified. Furthermore, in segregation analyses, the mutations always co-segregated with breast and ovarian cancer in the mutation positive families and the mutations have not been observed in any normal control individuals tested.

In summary, in a large, clinic based cohort of breast/ ovarian cancer families, $2.2 \%$ and $2 \%$ of previously BRCA1/2 mutation negative families were found to carry a large genomic rearrangement in BRCA1 and BRCA2, respectively, using a comprehensive testing methodology. As a result of this study, screening for large genomic rearrangements in $B R C A l / 2$ as part of a routine clinical, diagnostic service is highly recommended, especially in multiple case breast/ ovarian families with a young age of onset (BRCAl) and families containing at least one case of male breast cancer (BRCA2).

\section{ACKNOWLEDGEMENTS}

We thank Meryl Smith, Heather Thorne, Sandra Picken, Eveline Niedermayr, and Gulietta Pupo for assistance with family pedigrees, family information, and haplotype analysis; Heather Thorne, Dani Surace, and Lynda Williams for assistance with DNA preparation; Pamela Provan for help with real time PCR; Karen Byth for statistical support; Ilya Henner and Mark Wheeler for ABI analysis of the MLPA samples; and Christine Clarke, Dinny Graham, and Rosemary Balleine for helpful discussions.

\section{ELECTRONIC-DATABASE INFORMATION}

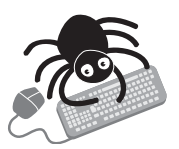

The webste of kConFab study can be found at www.kconfab.org, while that of MRC-Holland can be found at www.mrc-holland.com.

\section{Authors' affiliations}

A M Woodward, T A Davis, A G S Silva, J A Kirk, J A Leary, Familial Cancer Service, Westmead Institute for Cancer Research, University of Sydney at Westmead Millennium Institute, Westmead Hospital, Westmead, NSW 2145, Australia

kConFab Investigators, Kathleen Cuningham Consortium for Research into Familial Breast Cancer, Peter MacCallum Cancer Institute, St Andrews Place, East Melbourne, Victoria 3002, Australia

Supported by the University of Sydney Cancer Research Fund, the Western Sydney Area Health Service, Perpetual Philanthropic Foundations NSW. kConFab is supported by the National Breast Cancer Foundation, the National Health and Medical Research Council, and the State Cancer Councils of Australia.

Competing interests: none declared

Accession numbers (www.ncbi.nlm.nih.gov): BRCA1: U14680.1, L78833.1, AAA73985.1; BRCA2: U43746.1, Z74739.1, AAB07223.1.

Ethics approval for this study has been granted by the Western Sydney Area Health Service Human Research Ethics Committee and the University of Sydney Human Ethics Committee.

Correspondence to: Jennifer Leary, Familial Cancer Service, Westmead Hospital, Westmead, NSW 2145, Australia; jenny_leary@wmi.usyd. edu.au

Revised version received 21 December 2004

Accepted for publication 23 December 2004

\section{REFERENCES}

1 Szabo $\mathrm{Cl}$, King MC. Inherited breast and ovarian cancer. Hum Mol Genet 1995:4:1811-7.

2 Narod SA, Foulkes WD. BRCA1 and BRCA2: 1994 and beyond. Nat Rev Cancer 2004;4:665-76.

3 Hogervorst FB, Nederlof PM, Gille JJ, McElgunn CJ, Grippeling M, Pruntel R, Regnerus R, van Welsem T, van Spaendonk R, Menko FH, Kluijt I, Dommering C, Verhoef S, Schouten JP, van't Veer U, Pals G. Large genomic deletions and duplications in the BRCA'l gene identified by a novel quantitative method. Cancer Res 2003;63:1449-53.

4 Montagna M, Dalla Palma M, Menin C, Agata S, De Nicolo A, ChiecoBianchi L, D'Andrea E. Genomic rearrangements account for more than onethird of the BRCA1 mutations in northern Italian breast/ovarian cancer families. Hum Mol Genet 2003; 12:1055-61

5 Petrij-Bosch A, Peelen T, van Vliet $M$, van Eijk R, Olmer R, Drusedau M, Hogervorst FB, Hageman S, Arts PJ, Ligtenberg MJ, Meijers-Heiiboer H, Klijn JG, Vasen HF, Cornelisse CJ, van't Veer U, Bakker E, van Ommen GJ, Devilee P. BRCA1 genomic deletions are major founder mutations in Dutch breast cancer patients. Nat Genet 1997; 17:341-5.

6 Welcsh PL, King MC. BRCA1 and BRCA2 and the genetics of breast and ovarian cancer. Hum Mol Genet 2001;10:705-13.

7 Puget N, Torchard D, Serova-Sinilnikova OM, Lynch HT, Feunteun J, Lenoir GM, Mazoyer S. A 1-kb Alu-mediated germ-line deletion removing BRCA1 exon 17. Cancer Res 1997; 57:828-31.

8 Casilli F, Di Rocco ZC, Gad S, Tournier I, Stoppa-Lyonnet D, Frebourg T, Tosi M. Rapid detection of novel BRCAl rearrangements in high-risk breastovarian cancer families using multiplex PCR of short fluorescent fragments. Hum Mutat 2002;20:218-26.

9 Gad S, Caux-Moncoutier V, Pages-Berhouet S, Gauthier-Villars M, Coupier I, Pujol P, Frenay M, Gilbert B, Maugard C, Bignon YJ, Chevrier A, Rossi A, Fricker JP, Nguyen TD, Demange L, Aurias A, Bensimon A, Stoppa-Lyonnet D. Significant contribution of large BRCA1 gene rearrangements in 120 French breast and ovarian cancer families. Oncogene 2002;21:6841-7.

10 Puget N, Stoppa-Lyonnet D, Sinilnikova OM, Pages S, Lynch HT, Lenoir GM, Mazoyer S. Screening for germ-line rearrangements and regulatory mutations in BRCA1 led to the identification of four new deletions. Cancer Res 1999;59:455-61.

11 Unger MA, Nathanson KL, Calzone K, Antin-Ozerkis D, Shih HA, Martin AM, Lenoir GM, Mazoyer S, Weber BL. Screening for genomic rearrangements in families with breast and ovarian cancer identifies BRCA1 mutations previously missed by conformation-sensitive gel electrophoresis or sequencing. Am J Hum Genet 2000;67:841-50

12 Hofmann W, Gorgens H, John A, Horn D, Huttner C, Arnold N, Scherneck S, Schackert HK. Screening for large rearrangements of the BRCAl gene in 
German breast or ovarian cancer families using semi-quantitative multiplex PCR method. Hum Mutat 2003;22:103-4.

13 The BRCA1 Exon 13 Duplication Screening Group. The exon 13 duplication in the BRCAl gene is a founder mutation present in geographically diverse populations. Am J Hum Genet 2000;67:207-12.

14 Gad S, Klinger M, Caux-Moncoutier V, Pages-Berhouet S, Gauthier-Villars M, Coupier I, Bensimon A, Aurias A, Stoppa-Lyonnet D. Bar code screening on combed DNA for large rearrangements of the BRCA1 and BRCA2 genes in French breast cancer families. J Med Genet 2002;39:817-21.

15 Lahti-Domenici J, Rapakko K, Paakkonen K, Allinen M, Nevanlinna H, Kujala $M$, Huusko $P$, Winqvist R. Exclusion of large deletions and other rearrangements in BRCA1 and BRCA2 in Finnish breast and ovarian cancer families. Cancer Genet Cytogenet 2001;129:120-3.

16 Miki Y, Katagiri T, Kasumi F, Yoshimoto T, Nakamura Y. Mutation analysis in the BRCA2 gene in primary breast cancers. Nat Genet 1996; 13:245-7.

17 Nordling M, Karlsson P, Wahlstrom J, Engwall Y, Wallgren A, Martinsson T. A large deletion disrupts the exon 3 transcription activation domain of the BRCA2 gene in a breast/ovarian cancer family. Cancer Res 1998;58:1372-5

18 Peelen T, van Vliet M, Bosch A, Bignell G, Vasen HF, Klijn JG, MeijersHeijboer H, Stratton M, van Ommen GJ, Cornelisse CJ, Devilee P. Screening for BRCA2 mutations in 81 Dutch breast-ovarian cancer families. Br J Cancer 2000;82:151-6.

19 Wang T, Lerer I, Gueta Z, Sagi M, Kadouri L, Peretz T, Abeliovich D. A deletion/insertion mutation in the BRCA2 gene in a breast cancer family: a possible role of the Alu-polyA tail in the evolution of the deletion. Genes Chromosomes Cancer 2001;31:91-5.

20 Tournier I, Paillerets BB, Sobol H, Stoppa-Lyonnet D, Lidereau R, Barrois M, Mazoyer S, Coulet F, Hardouin A, Chompret A, Lortholary A, Chappuis P, Bourdon V, Bonadona V, Maugard C, Gilbert B, Nogues C, Frebourg T, Tosi M. Significant contribution of germline BRCA2 rearrangements in male breast cancer families. Cancer Res 2004;64:8143-7.

21 Wooster R, Weber BL. Breast and ovarian cancer. N Engl J Med 2003;348:2339-47.

22 Schouten JP, McElgunn CJ, Waaijer R, Zwijnenburg D, Diepvens F, Pals G. Relative quantification of 40 nucleic acid sequences by multiplex ligationdependent probe amplification. Nucleic Acids Res 2002;30:e57.

23 Couch FJ, DeShano ML, Blackwood MA, Calzone K, Stopfer J, Campeau L, Ganguly A, Rebbeck T, Weber BL. BRCA1 mutations in women attending clinics that evaluate the risk of breast cancer. N Engl J Med 1997;336: 1409-15.

24 Couch FJ, Farid LM, DeShano ML, Tavtigian SV, Calzone K, Campeau L, Peng Y, Bogden B, Chen Q, Neuhausen S, Shattuck-Eidens D, Godwin AK Daly M, Radford DM, Sedlacek S, Rommens J, Simard J, Garber J, Meraiver S, Weber BL. BRCA2 germline mutations in male breast cancer cases and breast cancer families. Nat Genet 1996;13:123-5.

25 Phelan CM, Lancaster JM, Tonin P, Gumbs C, Cochran C, Carter R, Ghadirian P, Perret C, Moslehi R, Dion F, Faucher MC, Dole K, Karimi S, Foulkes W, Lounis H, Warner E, Goss P, Anderson D, Larsson C, Narod SA, Futreal PA. Mutation analysis of the BRCA2 gene in 49 site-specific breast cancer families. Nat Genet 1996;13:120-2. 